\title{
Pelatihan Pembuatan Pupuk Organik dan Pakan Alternatif Ternak Bagi Kelompok Tani dan Karang Taruna Desa Bedono Karangduwur
}

\author{
Hanung Dhidik Arifin, Rina Widiastuti \\ Universitas Muhammadiyah Purworejo \\ Jl. KHA. Dahlan 3 dan 6 Purworejo, Jawa Tengah, Indonesia \\ *email: hanungdhidik@umpwr.ac.id
}

\begin{abstract}
Abstrak - Desa Bedono Karangduwur memiliki potensi bibit tanaman yang unggul, namun dalam proses perawatannya terkendala pada pemupukan. Petani maupun pembibit dalam teknik pemupukan belum menggunakan dosis anjuran. Melalalui kegiatan kuliah kerja nyata Universitas Muhammadiyah Purworejo di desa Bedono Karangduwur, melaksanakan program unggulan berupa pelatihan pembuatan pupuk organik dan pakan alternatif ternak. Peserta kegiatan ini adalah anggota kelompok tani dan karang taruna Desa Bedono Karangduwur. Hasil dari pelaksanaan kegiatan penyuluhan dan pelatihan ini berupa peengetahuan peserta pelatihan tentang pentingnya komposisi pupuk dalam proses pemupukan sehingga tanaman menajdi sehat dan subur. Luaran pelatihan berupa produk pupuk organik dan pakan ternak alternatif yang siap digunakan. Guna memberikan nilai ekonomis bagi warga, maka diberikan pula mekanisme labelling dan marketing terkait pupuk organik.
\end{abstract}

Kata Kunci: Pupuk organik, Alternative pakan ternak

\section{Training on Making Organic Fertilizer and Alternative Animal Feed for Farmer Groups and Youth Organization in Bedono Karangduwur}

\begin{abstract}
Bedono Karangduwur village has the potential for superior plant seeds, but in the maintenance process it is constrained by fertilization. Farmers and breeders in fertilization techniques have not used the recommended dose. Through real work lectures at the Muhammadiyah University of Purworejo in the village of Bedono Karangduwur, implementing a superior program in the form of training in making organic fertilizers and alternative animal feed. Participants in this activity are members of the farmer group and youth organization of Bedono Karangduwur Village. The result of this extension and training activity is in the form of knowledge of the training participants about the importance of fertilizer composition in the fertilization process so that plants become healthy and fertile. The output of the training is in the form of organic fertilizer products and alternative animal feed that are ready for use. In order to provide economic value to residents, a labeling and marketing mechanism is also provided related to organic fertilizers.
\end{abstract}

Keywords: Organic fertilizers and alternative feed livestock, Desa Bedono Karanguwur.

Article Info: Submitted: 04/06/2019 | Revised: 13/08/2019 | Accepted: 26/09/2019 


\section{PENDAHULUAN}

Indonesia merupakan negara dengan potensi sektor agraria yang tinggi yang tentunya sangat bergantung pada kesuburan tanah maupun lahan yang tersedia. Pemanfaatan lahan untuk memproduksi pangan maupun pakan perlu memperhatikan kelestarian kesuburan dan produktivitas lahan. Unsur hara tanaman yang digunakan atau diserap tanaman merupakan kehilangan bagi tanah dimana tanaman tersebut tumbuh. Pemupukkan lahan merupakan upaya mengganti unsur hara tanaman di dalam tanah yang telah diserap tanaman tersebut. Petani di Indonesia sebagian besar masih mengunakan cara bercocok tanam yang dilakukankonvensional terutama dalam penggunaan pupukyang hanya menggunakan pupuk buatan NPK saja (Haerul et al., 2015). Namun demikian, penggunaan pupuk anorganik secara terus-menerus dapat menyebabkan perubahan tekstur dan sifat fisika-kimia tanah yang cenderung menyebabkan adanya penimbunan unsur-unsur hara yang tidak mudah terlarut sehingga tidak tersedia bagi tanaman. Pemanfaatan lahan untuk pertanaman tanaman pangan maupun pakan juga akan menyebabkan penurunan kandungan bahan organik tanah.

Lahan dalam hal ini juga berlaku pada pembibitan tanaman baik yang berkayu maupun tidak, seperti contohnya desa dengan potensi pembibitan yang unggul di Kecamatan Kemiri yaitu Desa Bedono Karangduwur. Mayoritas penduduk Desa Bedono Karangduwur adalah pembibit tanaman berkayu, seperti bibit albasiah, bibit buah-buahan, bibit kelapa, dan bibit pohon jati. Maka dari itu, akan sangat disayangkan apabila potensi yang cukup besar diproses secara kurang menyeluruh dan mendasar. Salah satu hal mendasar dan vital dalam pembibitan adalah mengenai pemupukan. Pemupukan sangat menentukan dalam peningkatkan produktivitas tanaman. Petani maupun pembibit dalam teknik pemupukan saat ini sering kali melebihi dosis anjuran. Hal ini dikhawatirkan dalam jangka panjang dapat merusak sifat fisik, kimia, dan biologi tanah (Wahyunindyawati et al.,2012). Untuk menanggulangi hal tersebut, diperlukan suatu sistem pemupukan yang ramah terhadap lingkungan dan aman bagi tanaman. Pupuk organik dapat menjadi salah satu alternatif yang tepat dalam mengatasi permasalahan tersebut karena fungsinya yang dapat memberikan tambahan bahan organik, hara, memperbaiki sifat fisik tanah, serta mengembalikan hara yang terangkut oleh hasil panen. (Leovini, 2012)

Salah satu masalah dalam pelaksanaan pertanian organik adalah terbatasnya ketersediaan benih organik karena institusi penghasil benih belum memproduksi benih organik. Oleh karena itu, benih yang digunakan oleh petani organik, saat ini pada umumnya masih berupa benih konvensional (Anonim, 2002). Merujuk pada pemanfaatan pupuk organik dihasilkan oleh bahan-bahan alami salah satunya dari limbah ternak yang dipelihara oleh masyarakat. Memberikan pengetahuan dan wawasan kepada masyarakat tentang pentingnya penggunaan pupuk organik dan alternatif pakan agar meningkatkan mutu tanaman serta kualitas hidup ternak.

\section{METODE}

Metode Kegiatan pengabdian kepada masyarakat dalam bentuk penyuluhan dan pelatihan. Penyuluhan disampaikan dalam bentuk ceramah dan dialog interaktif atau diskusi, pelatihan dilakukan dengan melakukan praktik pembuatan pakan alternatif ternak. 
Kegiatan penyuluhan dan pelatihan ini merupakan rangkaian kegiatan pengabdian kepada masyarakat oleh dosen yang berkolaborasi dengan tim KKN desa Bodono Karangduwur, kecamatan Kemiri. Sebagai mitra dalam kegiatan pengabdian ini adalah segenap anggota kelompok tani dan karang taruna Desa Bedono Karangdhuwur.

Prosedur pada kegiatan pengabdian ini adalah diawali dengan kegiatan observasi, kemudian pelaksanaan dengan pemberian materi penyuluhan dan pelatihan kepada peserta, kemudian dilanjutkan tanya jawab seputar materi manajemen kesehatan ternak melalui pemberian jamu herbal fermentasi. Pelaksanaannya terdiri dari:

\section{Penyuluhan}

Memberikan penjelasan tentang pembuatan pupuk organik dan pakan alternatif ternak. Cara melakukan pembuatan pupuk organik, bahan dan alat yang digunakan dan cara pemberian setelah jadi serta diskusi dengan masyarakat.

2. Pelatihan

Pelatihan praktik secara langsung pembuatan pakan alternatif ternak.

Guna memperoleh gambaran tentang keterserapan pemahaman peserta pelatihan, dalam kegiatan pengabdian ini diberikan angket tentang kondisi riil di lapangan dalam sebagai bentuk observasi, lembar wawancara terhadap perangkat desa dan petani, serta instrumen pengamatan terhadap pelaksaanaan pelatihan. Data yang telah diperoleh dari hasil praktik, pengamatan, hasil tanya jawab dan tanggapan dari seluruh peserta yang mengikuti kegiatan pengabdian, selanjutnya data tersebut kemudian dilakukan analisis dengan analisis deskriptif.

\section{HASIL DAN PEMBAHASAN}

Sebagian besar masyarakat menganggap bahwa pemanfaatan pupuk organik seperti yang telah dipaparkan oleh narasumber serta fasilitator tidak efisien, karena yang diinginkan masyarakat adalah prospek jangka pendek, sedangkan untuk pupuk organik dan pakan alternatif merupakan tindakan yang dilakukan untuk prospek jangka panjang. Serta biaya yang digunakan untuk membuat pupuk organik dan pakan alternatif dapat dibilang cukup mahal. Hal tersebut merupakan anggapan masyarakat mengenai pupuk organik yang sebenarnya amat sangat disayangkan. Walaupun tidak menutup kemungkinan bahwa sebagian masyarakat sadar akan pentingnya penggunaan pupuk organik, terbukti salah satu kelompok tani telah menerapkan pembuatan pupuk organik yang digunakan untuk bibit berbagai macam tanaman. Alat dan bahan yang digunakan dalam kegiatan penyuluhan dan pelatihan agribisnis khususnya pemanfaatan pupuk organik ditunjukkan pada Tabel 1.

Tabel 1. Alat dan bahan pembuatan pupuk organik

\begin{tabular}{|l|l|}
\hline Alat-alat & Bahan yang digunakan \\
\hline 1. Terpal & 1. Feses kambing \\
2. Sarung tangan & 2. Sisa pakan \\
3. Ember & 3. Abu \\
& 4. Em4 \\
& 5. Polard \\
& 6. Kapur \\
\hline
\end{tabular}


Bahan-bahan tersebut dikumpulkan untuk kemudian dicampurkan ke dalam terpal dan didiamkan selama 4 minggu atau 1 bulan sebagai proses fermentasi untuk mendapatkan hasil yang diharapkan. Setelah bahan tersebut dicampurkan dan didiamkan proses selanjutnya adalah mengaplikasikan kedalam bibit tanaman yang membutuhkan tambahan pupuk.

Untuk hasil dari pembuatan pupuk organik yang dilakukan oleh mahasiswa KKN 06 Universitas Muhammadiyah Purworejo untuk saat ini masih belum mengalami peningkatan yang signifikan terhadap bibit yang menggunakan pupuk organik, sebab penggunaan pupuk organik ke tanaman tidak dapat di lihat dalam waktu yang singkat, akan tetapi membutuhkan waktu yang cukup lama agar hasil yang diperoleh dapat maksimal. Namun, menurut Rinasari et al. (2016) menyatakan bahwa pemupukan dengan pupuk organik yang dikombinasikan dengan pupuk anorganik pada perbandingan tertentu dapat meningkatkan kualitas dan kuantitas tanaman. Juhaeti dan Peni (2016) menambahkan pupuk organik mengandung bakteri pelarut fosfat dan bakteri penambat nitrogen yang mampu mengubah materi organik menjadi bentuk anorganik yang tersedia bagi tanaman. Dewi dan Jumini (2012) menyatakan, jika unsur hara dalam keseimbangan maka laju pertumbuhan dan kenaikan hasil cenderung meningkat. Jumlah daun yang dihasilkan dari setiap perlakuan sangat berpengaruh terhadap pertumbuhan vegetatif maupun generatif. Daun merupakan organ yang menunjang proses fotosintesis sehingga mampu menghasilkan makanan bagi pertumbuhan tanaman tomat (Sutoyo dan Hulopi, 2009). Oleh sebab itu, penggunaan pupuk organik sebenarnya akan memberikan kelebihan selain bagi lingkungan, juga baik bagi ertumbuhan tanaman itu sendiri. Selain kelebihan, pupuk organik juga memiliki kelemahan, bahwa dengan penggunaan pupuk organik unsur hara sangat lambat tersedia sehingga perlu dikombinasikan dengan pupuk anorganik yang menyediakan unsur hara dengan cepat (Pangaribuan et al., 2012).

Hasil dari pelaksanaan kegiatan penyuluhan dan pelatihan pembuatan pupuk organik dan pakan ternak, yakni para kelompok tani Desa Bedono Karangduwur mengetahui pemanfaatan limbah organik, mendapatkan ilmu baru tentang cara mengolah limbah organik menjadi pupuk organik ramah lingkungan dan pakan alternatif ternak. Dengan diadakannya penyuluhan dan pelatihan tersebut diharapkan dapat membantu kelompok tani pada khususnya untuk mengolah dan memanfaatkan limbah organik menjadi pupuk organik maupun pakan alternatif ternak yang ramah lingkungan. Dokumentasi kegiatan disajikan pada Gambar 1.

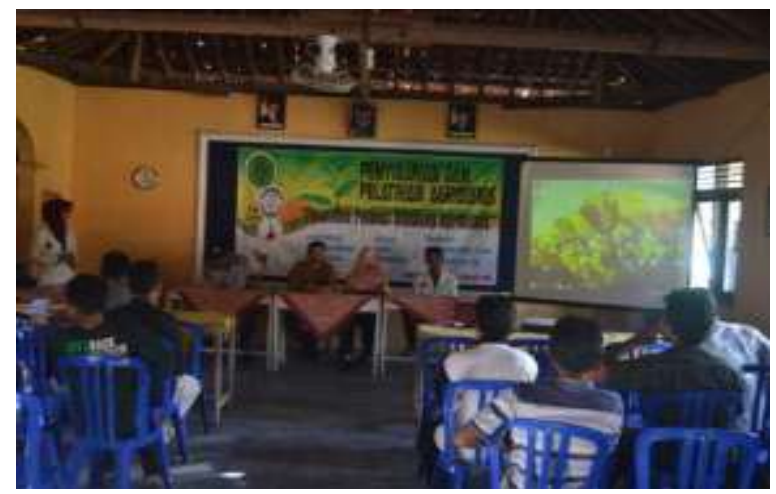

Gambar 1. Dokumentasi pelaksanaan penyuluhan 
Selain melakukan penyuluhan, Bapak Hanung dan Ibu Rina dibantu bersama mahasiswa Kuliah Kerja Nyata UMP juga mempraktikkan cara pembuatan pupuk organik dan pakan alternatif ternak. Hal ini dilakukan agar para kelompok tani Desa Bedono Karangduwur lebih memahami cara pembuatan pupuk organik dan pakan alternatif tersebut. Pelatihan pembuatan pupuk organik dan pakan alternatif ternak bertujuan untuk melatih para kelompok tani yang belum mengetahui tentang cara pengolahan dan pemanfaatan limbah organik menjadi pupuk organik dan pakan alternatif. Selain itu, dengan pelatihan ini diharapkan dapat membantu kelompok tani Desa Bedono Karangduwur dalam mengolah limbah organik sebagai persediaan pupuk organik dan pakan alternatif. Proses praktek pembuatan pupuk organik ditampilkan pada Gambar 2.

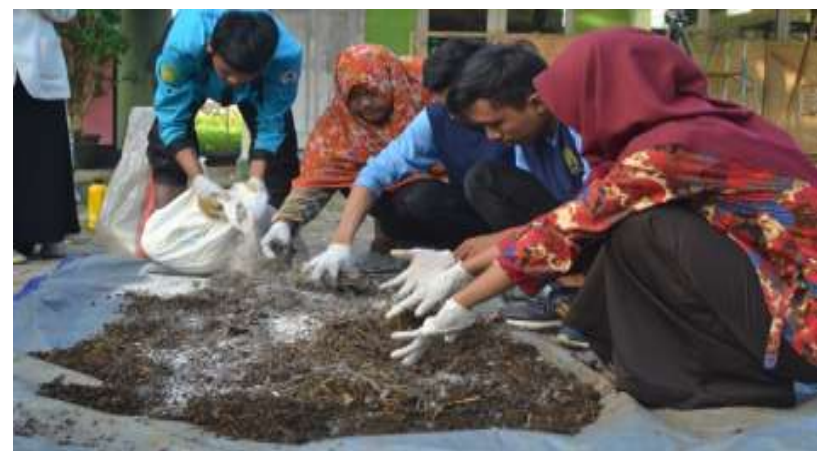

Gambar 2. Dokumentasi Praktik Pembuatan Pupuk Organik dan pakan Alternatif

Hasil dari pembuatan pupuk organik dan pakan alternatif ternak ini berupa produk pupuk organik dan pakan alternatif yang siap digunakan. Selain untuk digunakan dalam bidang pertanian, pupuk organik dan pakan alternatif dapat dijadikan sebuah peluang usaha yang dapat menambah nilai jual dan ekonomis limbah organik. Jika dikemas dengan baik dan menarik, produk pupuk organik dan pakan alternatif ini dapat dipasarkan dan dapat menambah pendapatan rumah tangga. Dokumentasi kegiatan disajikan pada Gambar 3.

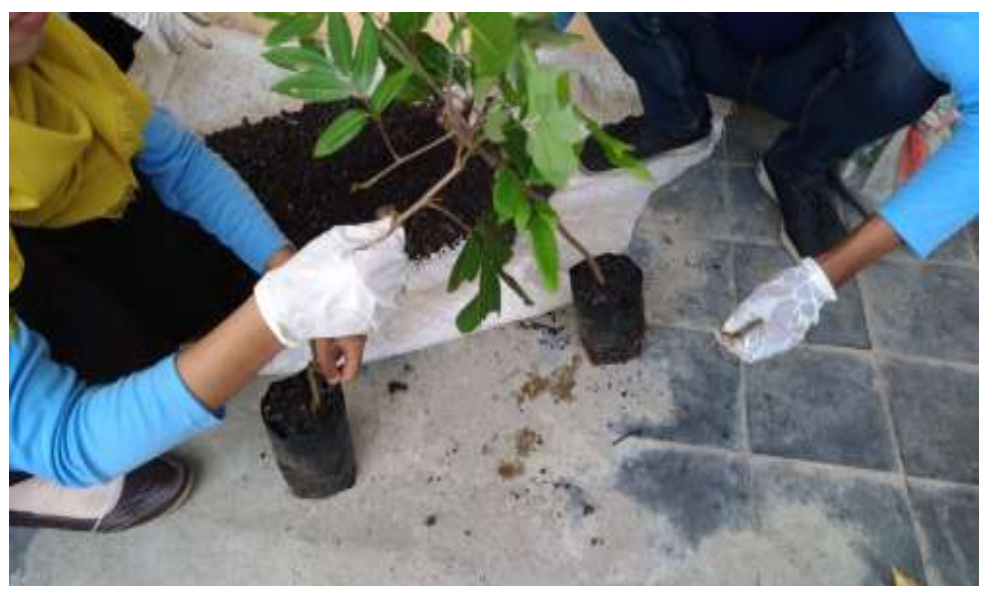

Gambar 3. Dokumentasi penggunaan hasil pupuk organik 


\section{KESIMPULAN}

Kegiatan pengabdian kepada masyarakat dalam bentuk penyuluhan dan pelatihan pembuatan pupuk organik dan pakan ternak alternative telah terlaksana dengan baik sesuai rencana. Peserta dapat mengikuti penyuluhan dan pelatihan dengan baik sehingga diharapkan dapat menerapkan pengetahuan yang diperoleh dalam pengolahan budidaya tanaman dan pembibitan dengan lebih baik. Melalui mekanisme pembuatan pupuk organik yang telah di berikan, masyarakat diharapkan dapat mengembangkan secara mandiri terutama untuk dibuat labelling maupun marketing sebagai nilai tambah ekonomi warga. Dengan adanya kegiatan penyuluhan dan pembuatan pupuk organik dan pakan alternatif ternak diharapkan para kelompok tani di Desa Bedono Karangduwur dapat lebih memanfaatkan limbah organik sebagai olahan yang dapat menambah pendapatan rumah tangga serta dapat digunakan sebagai pupuk organik dan pakan ternak alternatif yang ramah lingkungan.

\section{DAFTAR PUSTAKA}

Anonimous. 1983. Hijauan Makanan Ternak. Kanisius: Yogyakarta.

Anonim. 2002. Prospek Pertanian Organik di Indonesia. http://www.litbang.deptan.go.id/berita/one/17/. Diakses pada tanggal 05 April 2018.

Dewi, P. Dan Jumini. 2012. Pertumbuhan danHasil Dua Varietas Tomat Akibat PerlakuanJenis Pupuk. Jurnal Floratek $7: 76-84$.

Haerul, Muammar, dan J. L. Isnaini. 2015. Pertumbuhan dan produksi tanaman tomat (Solanum lycopersicum L.) terhadap POC(Pupuk Organik Cair). J. Agrotan 1(2) : 69-80.

Juhaeti, T dan L. Peni. 2016. Pertumbuhan,produksi dan potensi gizi terong asalenggano pada berbagai kombinasiperlakuan pemupukan. Berita Biologi15(3) : 303-313.

Leovini, H. 2012. Pemanfaatan pupuk organik cairpada budidaya tanaman tomat (Solanumlycopersicum L.). Makalah Seminar Umum Program Studi Agronomi Universitas Gadjah Mada. Yogyakarta.

Machfud, M., Soenardi, F. T. Kadarwati. 1996. Pengaruh Dosis Pupuk N dan P Terhadap Pertumbuhan Dan Hasil Wijen Galur Pachequin di Lahan Tadah Hujan. Jurnal Littri 2: 43-49.

Pangaribuan, D. H., M. Yasir, dan N. K. Utami.2012. Dampak bokashi kotoran ternakdalam pengurangan pemakaian pupukanorganik pada budidaya tanaman tomat. J.Agron. Indonesia 40 (3) : 204-210.

Rinasari, S. P. O., Z. Kadir, dan Oktafiri. 2016.Pengaruh Konsentrasi PupukOrganonitrofos terhadap Pertumbuhan danProduksi Tanaman Tomat (Lycopersiconesculentum Mill.) secara Organik denganSistem Irigasi Bawah Permukaan (SubSurface Irrigation. Jurnal Teknik PertanianLampung 4 (4) : 325-234.

Sutoyo dan F. Hulopi. 2009. Pengaruh pupukorganik supernasa pada berbagai dosis danfrekwensi terhadap pertumbuhan dan hasiltanaman tomat. Buana Sains 9 (2) : 153158. 
Volume 3 Nomor 2, Oktober, 2019, pp: 57-63

Available online at: http://jurnal.umpwr.ac.id/index.php/abdimas p-ISSN: 2580-3492 e-ISSN: 2581-0162

Wahyunindyawati, F. Kasijadi dan Abu. 2012. Pengaruh Pemberian Pupuk Organik “Biogreen Granul" Terhadap Pertumbuhan dan Hasil Tanaman Bawang Merah. Journal Basic Science and Technology 1: 21-25. 